\title{
Organization of an Endoscopic Division
}

\author{
C.E. Legorini1, G.F. Milani1, S. Calabro2
}

Monaldi Arch Chest Dis 2011; 75: 1, 8-13.

Keywords: Quality management system, Risk management, Incident reporting system, Process approach, Quality indicators.

1 SOC di Pneumologia, Ospedale S. Maria della Misericordia, Az ULSS 18 Rovigo,

2 S.C. Pneumologia, Ospedale San Bassiano, ULSS 3 Bassano del Grappa, Italy.

Correspondence: Dr. C.E. Legorini, SOC di Pneumologia, Ospedale S. Maria della Misericordia, Az ULSS 18 Rovigo, Via Tre Martiri 140, 45100 Rovigo, Italy; e-mail: legorini.cristina@azisanrovigo.it

\section{Introduction}

The word "Organisation" can be defined as either "An organized group of people with a particular purpose, such as a business or government department; the quality of being systematic and aefficient" [1], the predominant factor being its systematic nature. Several factors therefore need to be considered: structure; technology; science; security; qualification; training; communication; relationships; management and human diversity.

In addition, there are a number of factors which complicate the issue, for instance, laws and regulations, national and regional directions regarding authorisation, accreditation, and risk management; instructions on the establishment of quality systems and on the realisation of diagnostictherapeutic paths, and, finally, economic and management aspects.

\section{Rationale}

Many of the topics set out above have been widely dealt with in "The Guidelines of the studying group for thoracic endoscopy AIPO" [2] in 1997 and the result of this study is still valid and relevant. However, the new inputs, as stated above, have determined new issues which have been evaluated by gathering together all the available literature and by considering experiences in the field in some important centres for respiratory endoscopy in Italy. Our attempt has been to suggest a systematic management approach within a Respiratory Endoscopy Division. We have therefore tried to identify the common aspects in every regulation and reference guidance.

\section{Means analyzed}

\section{Quality Management Systems}

The Quality Management System is part of every organisation's management. In the industrial field, for instance, the 'Process' approach is one adopted: the organization is seen as a cluster of processes, interconnected and managed by a quality system. The reference models for a quality management system are varied, and the experience in Italy within the thoracic endoscopic divisions refers to the following regulations:

- ISO International Organization for Standardization [3-6],

- Joint Commission for Accreditation of Healthcare Organization [7],

- Pilot testing within PQI (Italian Quality Prize) and IQRS "International Quality Rating System" $[8,9]$.

We have evaluated these models identifying the features that are common to all of them. All the above regulations require the analysis of the processes and of the interactions among them, the presence of written procedures and indicators together with a continual improvement activity, measured through the customer satisfaction and that of other interested parties.

\section{National and regional dispositions to obtain the institutional accreditation of the Healthcare structures}

\section{National level}

Laws and documents at a National level ${ }^{1}$ indicate the progressive steps that need to be devel-

1 “D.lg. 502/92 Titolo II, art.10, D.lg.del 24/07/1975, art.1, DPR n.37 del 14/1/1997 “Approvazione dell'Atto di indirizzo e coordinamento alle regioni e alle P.A. di Trento e Bolzano, in materia requisiti strutturali, tecnici ed organizzativi inimi per l'esercizio delle attività sanitarie da parte di strutture pubbliche e private", DLgs 229 del 19/06/1999 "Norme per la razionalizzazione del SSN a norma dell'art.1 della legge 30 novembre 1998, n.419", Legge Costituzionale 3/2001 "Riforma del Titolo V della Costituzione", Piano Sanitario Nazionale 2002-2004". 
oped; to define a method for monitoring and reviewing quality, to correctly use monitoring devices, and to define the criteria to obtain an accreditation of the healthcare structures.

The basic standard to obtain accreditation is that it is not possible to provide a service of quality when systematic structure and technical- professional procedures are lacking. These are necessary to guarantee the desired quality in a defined environment. Within this context, the Italian Regions have considered various models of organisation and quality management. We have evaluated the following:

\section{Regional level}

At a Regional level there are laws and regulations from the Veneto, Emilia-Romagna and Lombardia Regions.

Veneto Region Law 16 August 2002 (L.R. 16 agosto 2002 (BUR $n$. 82/2002) e relativo Manuale di attuazione), and in particular the implementation manual, focuses on the Continual Improvement Process and stresses the importance of establishing "an underlying operative quality system that can be recognized and shared" - containing indications for the continual quality improvement, containing procedures, guidelines and operative instructions for all the activities. References are: MCQ method, legge 22/2002, UNI EN ISO 9001:2000.

Emilia-Romagna Region Resolution $n$. 327, 23 February 2004, the 97-2004 dossier, which contains the guidelines for the accreditation, broadly refers to the regulation UNI EN ISO 9001:2000 and is subdivided in 10 areas: politics, planning, communication, structure, equipment, training, information system, procedures, results measurement, and improvement [10].

Lombardia Region issued the Law DGR 38133 , 6 August 1998 "additional requirements" DGR46582 26/11/99 "identification of areas and first indicators to carry out the quality system in the healthcare structures in Lombardia". The DGR.3141 del $19 / 1 / 2001$ has re-defined the strategies in the Lombardia region which are relevant to the quality system, promoting the "excellence accreditation" of the healthcare structures, according to JCAHO model (Joint Commission on Accreditation of Health Care Organizations) which emphasises the quality of the healthcare services provided.

\section{Risk management instruments}

DPR 23/5/2003, art. 1.2 "The healthcare system must strengthen methods and instruments to handle risks, prevent and face external threats, and mend possible damages".

Here are some of the possible risks within the healthcare system [11]: occupational risk, "non clinical" risk, clinical risk, which includes structural risk (structures, equipment), organisational risk (delays, lack of procedures) and mistakes by physicians and health services providers.

Obviously it is essential to strictly comply with all the security regulations and to observe all the indications of the Scientific Institutes as far as procedures are concerned.
But the risk management process, according to literature and experience, appears to be more complex and is divided into three steps which need to be constantly monitored: identification, analysis and evaluation, and solution.

To facilitate this process, we refer to the existing management techniques and to the models to monitor these aspects in all their complexity [11].

The experiences relevant to the use of risk management instruments by the Italian Endoscopic Thoracic Structures refer to the management of non-compliant quality systems according to the ISO requirements, to the quality and security improvement programme in those systems which refer to the Joint Commission, and to the Incident Reporting according to the method proposed by Emilia-Romagna and Veneto Regions.

\section{A) Divisions with implemented quality system:}

ISO requirements prescribe the re-evaluation of the quality by the person responsible who utilise three instruments: 1) registration of the non conformity (compliance), 2) collection and recurrent analysis of the collected data, 3) definition of the preventive/ corrective measures and monitoring of the results according to the non conformity management procedure.

The Joint Commission requirements include a constant monitoring action by the person responsible for processes and surveillance indicators and also the checking and prevention of actions which may threaten the patients and personnel's security.

In both cases a quality system is implemented by adopting the method known as the "Plan-DoCheck-Act" (PDCA) one, with the underlying goal of continual improvement.

\section{B) Incident Reporting System [12]:}

This is a method of data collection of unexpected events and provides a basis for the implementation of corrective actions designed to avoid the repetition of such events and to reduce as much as possible their consequences. This method was born in the aviation field and it has been utilized for some years in the Anglo-Saxon healthcare systems (USA, United Kingdom and Australia) with several important completed and ongoing trials.

The Emilia Romagna Region and some Healthcare companies in Veneto, have initiated, as an experiment, the reporting of events and near miss events by means of a notification form on a voluntary basis, compiled by health-care personnel. The incident reporting system is indicated as one of the instruments of the first phase of the "risk management" process, i.e. the identification, which is followed by the evaluation phase, which utilises other methods (Root cause analysis, Clinical Audit, FMEA, and FMECA) and the corrective action phase. Such instruments have been utilised in the health-care organisations with effectiveness evidence on an international basis [13].

In both experiences we deal with voluntary approaches based on the spontaneous notification by health-care personnel, implying the existence of an 
organisational process approach, data gathering, and systematic data evaluation.

\section{Aspects common to all the analysed means}

The three types of instruments considered are quality management systems, National and Regional dispositions to obtain the institutional accreditation of the Healthcare structures, and the instruments for the risk management. These instruments give us some basis on which we can begin to work, regardless of the iter that each structure shall follow because of the indications and dispositions of the corporate strategies.

\section{Process approach}

It is evident that the process approach is essential for every type of instrument considered.

Process is herein defined as a set of interrelated or interacting activities which transforms inputs into outputs [3]. Inputs in one process are often outputs of other processes.

The 'process' approach is herein defined as the choice of a process system in an organisation. Processes must be identified by describing their flow and their interacting activities. Appropriate resources must be allocated, process effectiveness and efficiency must be assessed. One of the advantages of this approach is that each activity can be constantly monitored and measured while interacting to achieve more efficiently the desired result [5].

\section{Recommendation}

- A process approach is recommended in organizing and Endoscopic Thoracic Division, where the service provided to the patient, from the exam booking to the medical report delivering, represents the "main flow of interrelated processes". To this, support activities concur to the final result.

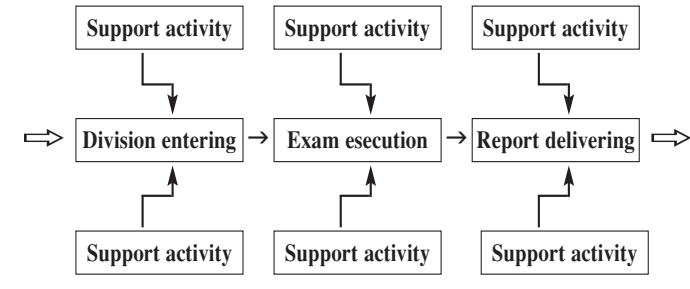

We advise to organize support activities in processes able to guarantee results which allow an efficient functioning of the processes aimed to thoracic endoscopic services (Grade C).

\section{Documentation}

Written documents are always required and in particular, procedures are fundamental as reference models.
Procedure is here defined as a "specified way to carry [14] out an activity or a process [3]". Procedures are instruments by which means a structure carries out its activities in the most systematic, monitorable and objective way, especially when such activities are complex and articulated.

The mapping of the process is fundamental because it identifies and describes each activity. When a process is particularly complex it is advisable to establish a document priority, where, for particular activities, more operative instructions may be referred to [15]. Moreover procedures may refer to Scientific Institutes guidelines in relation to more technical aspects [16]. Should local guidelines be necessary, a careful drawing is recommended [17]. Finally all documents are linked to other modules or whatever necessary for the registration. Other "miscellaneous" documents may be drafted if they are believed useful by the person in charge.

\section{Recommendation}

- We recommend process documentation through procedures.

The procedure system should be adequate to the activities to be performed and systematically updated and improved.

Simple procedures which refer to guidelines and operative instructions are suggested (Grade C).

\section{Risk management}

In the health-care field $85 \%$ of the adverse events and near miss events are due to organisation and system deficiencies. Therefore a risk management programme is useful and necessary, as widely suggested. The clinical risk management is a proposed systematic process of identification and handling of the real and potential risks by the health-care assistance and becomes an important part of the quality systems.

Events, near miss events and alarm events must be identified, documented, analysed and evaluated in order to avoid or reduce them. We suggest using instruments and methods generally applied in continually improving quality, adjusting them to the specific area [18].

\section{Recommendation}

- We recommend implementing a risk management instrument which systematically identifies registers, analyses, handles and prevents events, near miss events and alarm events. Possible instruments are the non-conformity management procedure or the incident reporting system, with relevant analysis and usage methods (Grade $\mathrm{C}$ ). 


\section{Indicators, monitoring and improvement}

The definition of organisation as an interrelated process system implies monitoring and measurement activities of such processes and of their results. For this reason the word "indicator" is often used in the examined documentation [19]. Indicator is herein defined as "selected information aiming at measuring changes occurring in the observed phenomena and consequently addressing decisional processes at various institutional levels" [20].

For each indicator we suggest that the following are listed: definition, methods, responsibility, measurement frequency and the reference standard in particular of the Scientific Institutes Guidelines [21, 22], a possible range [21]. Perceived quality is an indicator present in all the evaluated systems. It can be defined as the patients' perception on how much their needs have been satisfied. Questionnaires - ad hoc for endoscopic structures - have periodically been conducted and have proved to be useful instruments in order to improve quality [23, 24].

\section{Recommendation}

- We recommend defining process and product indicators.

As for procedures it is advisable to arrange an indicator system adequate to the activities to be performed. The reference standard for the diagnostic effectiveness of the endoscopic services and its complications should be searched in literature, particularly in Scientific Institutes Guidelines. An instrument to register quality as perceived by patients is recommended (Grade $\mathrm{C}$ ).

The organisation of an endoscopic division as set out above systematically provides the person in charge with data relevant to all the defined indicators, non-conformities, possible further data regarding risk management, complaints, perceived quality, possible results of internal/external tests on implemented quality systems.

The analysis of the gathered data is essential to correct, prevent and improve both management and professional aspects and can thus be used to plan the division activities.

The method suggested in this phase is the model known as PDCA. It is recommended to always register the periodical analysis, the data evaluation, and the corrective, preventive and improving actions, which have been carried out.

\section{Recommendation}

- We recommend the systematic evaluation of the data and information gathered, and the subsequent planning of corrective, preventive and improving actions (Grade $\mathrm{C}$ ).

\section{Patient as the focal point}

The whole division is aimed at satisfying the patient's needs through the definition and monitoring of the services provided, even those services which the patient may not be able to evaluate. Therefore, as already highlighted, information on the perceived quality is to be included into the indicators which are part of the continual improvement process.

We recommend preparing the following:

\section{Service chart}

The service chart may refer to the endoscopic division or be integrated in the Pneumological department.

It is a public document in which the division lists the services provided and the level of quality and quantity guaranteed. For information on how to draft the chart, please refer to the literature suggested $[4,10,25]$.

\section{Informative documents for the patient to facilitate the obtaining of the consent}

These documents are drafted to support the correct obtaining of consent. International Guidelines indicate [26], with B evidence degree, a better tolerance to the endoscopic exam in those patients who have received correct information in both verbal and written forms. We suggest the compiling of exhaustive documents but at the same time concise and easily comprehensible.

\section{Recommendation}

- We recommend the availability of the Service chart, of informative leaflets on the different endoscopic methods, to be utilised as supports to obtain the consent (Grade B).

\section{Conclusions}

Despite the incompleteness of what has be set out thus far, the differences among health-care situations and the diversity in which endoscopists have to work, and the lack of ad-hoc literature, we believe we can recommend the reference to systematic methods and in particular to the models analysed. All the documents for which a draft is suggested, describe a routine activity for a thoracic endoscopic division, their application is of use if they are adjusted to the specific situation and therefore can be utilised both by the health worker and by the person in charge of checking, identifying weaknesses, and consequently planning preventive / corrective / improvement actions.

Independently from the regulation to which one may refer to and from the choice to apply or not for the accreditation, we believe that a quality system, complying with the laws, with corporate indications, with the Scientific Institutes guidelines, and enriched with one's personal experience, is funda- 
mental to define, monitor, update, correct and improve the activity of an thoracic endoscopic division. It is therefore a means to be recommended to sustain and promote good organisational practices.

\section{Summary of Recommendations}

- A process approach is recommended in organizing an Endoscopic Thoracic Division, where the service provided to the patient, from the exam booking to the medical report delivering, represents the "main flow of interrelated processes". To this, support activities concur to the final result.

We advise to organize support activities in processes able to guarantee results which allow an efficient functioning of the processes aimed to thoracic endoscopic services (Grade $\mathbf{C}$ ).

- We recommend process documentation through procedures.

The procedure system should be adequate to the activities to be performed and systematically updated and improved.

Simple procedures which refer to guidelines and operative instructions are suggested (Grade $\mathbf{C}$ ).

- We recommend implementing a risk management instrument which systematically identifies registers, analyses, handles and prevents events, near miss events and alarm events. Possible instruments are the non-conformity management procedure or the incident reporting system, with relevant analysis and usage methods (Grade C).

- We recommend defining process and product indicators.

As for procedures it is advisable to arrange an indicator system adequate to the activities to be performed. The reference standard for the diagnostic effectiveness of the endoscopic services and its complications should be searched in literature, particularly in Scientific Institutes Guidelines. An instrument to register quality as perceived by patients is recommended (Grade $\mathrm{C}$ ).

- We recommend the systematic evaluation of the data and information gathered, and the subsequent planning of corrective, preventive and improving actions (Grade C).

- We recommend the availability of the Service chart, of informative leaflets on the different endoscopic methods, to be utilised as supports to obtain the consent (Grade B).

\section{References}

1. Oxford Dictionaries Online. Oxford University Press. 2011. oxforddictionaires.com

2. Gruppo di Studio AIPO "Endoscopia Toracica". Standard operativi e linee guida in endoscopia toracica. Rassegna di Patologia dell'Apparato Respiratorio 1997; 12: 293-355.

3. UNI EN ISO 9000 Sistemi di gestione per la qualità Fondamanti e terminologia - 2000.

4. UNI EN ISO 9001 Sistemi di Gestione per la qualità requisiti.

5. UNI EN ISO 9004 Sistemi di Gestione per la qualità Linee Guida per il miglioramento delle prestazioni.

6. Milani GF, Legorini C, Pivirotto F. Quality management system in a respiratory endoscopy service. The implementing process of the UNI EN ISO 9001:2000 (Vision 2000). Eur Respir J 2002; 20 (Suppl.): P2915.

7. Joint Commission for Accreditation of Health Care Organisations, http//jcaho.org

8. DNV-IQRS; http://dnv.it/certificazione/riskmanagement/IQRS.

9. PQI Guida alla partecipazione e all'autovalutazione Livello Nazionale 2001.

10. Agenzia Sanitaria Regionale Emilia Romagna Il sistema qualità per l'accreditamento istituzionale in EmiliaRomagna. Collana Dossier 97-2004 in http://www.regione.emilia-romagna.it/agenziasan/colldoss/index.htm

11. Cinotti R. La gestione del rischio: un approccio di sistema. In: La gestione del rischio nelle organizzazioni sanitarie, parte prima, p. 15, Il Pensiero Scientifico Editore 2004.

12. Agenzia Sanitaria Regionale Emilia Romagna. Il sistema di incident reporting nelle organizzazioni sanitarie. Sussidi per la gestione del rischio 2. Collana Dossier 86-2003 in http://www.regione.emilia-romagna.it/agenziasan/ colldoss/index.htm

13. Agenzia Sanitaria regionale Emilia Romagna. Sussidi per la gestione del rischio n.1 FMEA-FMECA collana dossier n.75.2002. in http://www.regione.emilia-romagna.it/agenziasan/colldoss/index.htm

14. Decreto del Presidente della Repubblica 14 gennaio 1997 n. 37. Approvazione dell'atto di indirizzo e coordinamento alle regioni e alle province autonome di Trento e di Bolzano, in materia di requisiti strutturali, tecnologici ed organizzativi minimi per l'esercizio delle attività sanitarie da parte delle strutture pubbliche e private. DPR 37.14.97.

15. Franchini A. La documentazione dei processi attraverso le procedure. Sussidi per l'autovalutazione e l'accreditamento 3. Agenzia Sanitaria Regione Emilia Romagna, novembre 1998 in http://www.regione.emilia-romagna.it/agenziasan/colldoss/index.htm

16. Lazzari Agli L, Casalini AG, Consigli G, et al. Linee Guida sulle procedure di manutenzione degli strumenti endoscopici. Rassegna di Patologia dell'Apparato Respiratorio 2003; 18: 376-390.

17. Manuale Metodologico Piano Nazionale Linee Guida. Come produrre, diffondere ed aggiornare raccomandazioni per la pratica clinica. 2002, aggiornamento 2004.

18. Perraro F. Presentazione in: La Gestione del rischio clinico. A cura di F. Novaco e V. Damen, Centro Scientifico Editore 2004, XI-XIV.

19. Indicatori - Decreti del Ministero Sanità del 24/7/95 e del 15/10/96.

20. D.M. 11 aprile 1994.

21. Legorini CE, Milani GF. The indicators plan for the quality system monitoring in a Respiratory Endoscopy Service. Eur Respir J 2005; 26 (Suppl. 49): P2105.

22. Birkner B. Cerification of an ambulatory gastroenterologic service fulfilling ISO Law 9001-criteriaand national guidelines of the Gastroenterologic Association. Z Arztl Fortbild Qualitatssich 2000; 94: 639-43. 
23. Legorini CE, Rinolfi A, Milani GF, Piron P, Fornasari E. The evalutation of customer satisfaction in a Respiratory Endoscopy Service. Eur Respir J 2005; 26 (Suppl. 49): P3441.

24. Lechtzin N, Rubin HR, Jenckes M, et al. Predictors of pain control in patients undergoing flexible bronchoscopy. Am J Respir Crit Care Med 2000;162: 440-445.
25. Carta dei Servizi - Linee Guida n.2/95 del Ministero della Sanità.

26. British Thoracic Society Bronchoscopy Guidelines Committee, a Subcommittee of Standards of Care Committee of British Thoracic Society. British Thoracic Society guidelines on diagnostic flexible bronchoscopy. Thorax 2001; 56 Suppl 1: i1-21.

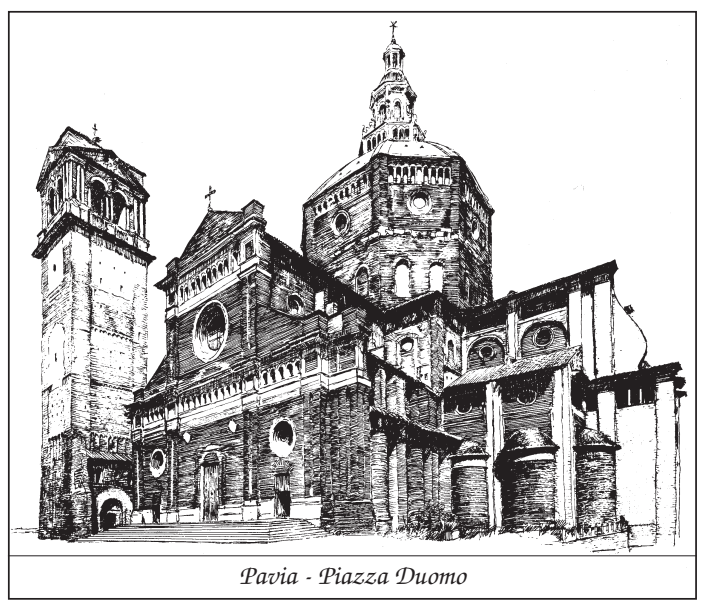

